\title{
Dysfunctional impulsivity in online gaming addiction and engagement
}

\author{
Lukas Blinka, Kateřina Škařupová, Kristina Mitterova \\ Faculty of Social Studies, Masaryk University, Brno, Czech Republic
}

\begin{abstract}
Impulsivity has been shown to be related to both substance- and non-substance addictions. In the case of internet gaming addiction, on one hand, higher impulsivity and sensation seeking have been reported in problematic online gamers. On the other hand, problematic online gamers were also identified as introverted, socially anxious, and generally inhibited in behaviour. Our study investigates the role of dysfunctional impulsivity in gaming addiction. A sample of 1,510 Czech and Slovak online gamers completed a questionnaire that was advertised online and targeted the core of the gaming community. Internet gaming addiction was measured using the Addiction-Engagement Questionnaire (Charlton \& Danforth, 2010). Dysfunctional impulsivity was measured using the 11 items of Dickman's (1990) sub-scale of the Impulsivity Inventory. Pearson's correlation coefficients were calculated for variables and a regression model was constructed using hierarchical linear regression to determine the association between online gaming addiction and dysfunctional impulsivity, while controlling for age, gender, and the frequency of online gaming. A set of chi-square tests was employed to compare the patterns of addiction criteria among highly impulsive addicted gamers and non-impulsive addicted gamers. Although dysfunctional impulsivity was a good predictor of gaming addiction $(\beta=.252)$, it actually explained only about $7 \%$ of the addiction variance. Problematic gamers high on impulsivity had similar patterns of addiction criteria as non-impulsive gamers, with only one exception - they had a significantly higher tendency to relapse. There was no role of impulsivity in gaming engagement. The results suggest that dysfunctional impulsivity is a risk factor for online gaming addiction (similar to other addictions), but it does not have prominent explanatory value in itself. Also, the results show that problematic gamers high on impulsivity are more prone to relapse and reinstatement.
\end{abstract}

Keywords: Dysfunctional impulsivity; impulsivity; gaming engagement; gaming addiction; internet gaming disorder

\section{Introduction}

The American Psychiatric Association created a category called "Substance Related and Addictive Disorders" in its fifth revision of the Diagnostic and Statistical Manual of Mental Disorders (American Psychiatric Association, 2013). This category now includes gambling, which was previously understood as an impulse control disorder. The revision also suggested Internet Gaming Disorder as a related condition for further study. Impulsivity and addictions share some of the core features (Potenza, 2006) and understanding the role of impulsivity in internet gaming may produce important information for the understanding and conceptualization of excessive online play as a behavioural addiction. A number of neuroimaging studies found support for shared neurocircuitries between behavioural and substance addictions, with neurotransmitter systems contributing to shared involvement in addiction- and impulsive-control disorders (c.f. for review Grant, Potenza, Weinstein, \& Gorelick, 
2010; Lubman, Yücel \& Pantelis, 2004; Volkow, Fowler \& Wang, 2003). A core set of frontostriatal circuits was found in various types of impulsivity, substance addiction (Jentsch et al., 2014), and pathological gambling (elGuebaly, Mudry, Zohar, Tavares, \& Potenza, 2011). Jentsch et al. (2014) have shown a strong relationship between impulsivity and addiction-related behaviours, and also the potential susceptibility of those with poor impulse control for substance or behavioural addiction. Indeed, impulsivity was associated with both substanceand non-substance addictions in some studies (Maccallum, Blaszczynski, Ladouceur, \& Nower, 2007; VerdejoGarcía, Lawrence, \& Clark, 2008). However, this may not be fully true in the case of internet gaming disorder as the evidence to date provides limited outcomes; according to the American Psychiatric Association, its status as an addiction needs more research. Understanding the role of impulsivity in online gaming addiction may be an important contribution in the conceptualization of excessive gaming as a behavioural addiction.

Higher impulsivity was found to be a risk factor for becoming a pathological gamer in a longitudinal study by Gentile et al. (2011). Liau et al. (2015) showed the association of impulsivity and low self-regulation with gaming addiction. And, in a comparative study by Walther, Morgenstern, and Hanewinkel (2012), higher levels of impulsivity was the only predictor of problematic gaming shared with other addictions, such as gambling, and with the use of tobacco, alcohol, and cannabis. Problematic internet gamers had distinct personality types compared to those with other addictions, e.g. they were younger, less extroverted, and showed higher levels of social anxiety. In a small clinical sample, Choi et al. (2014) found that overall impulsivity was higher in addicted gamers than in both gamblers and a healthy control group. A number of studies also pointed out that online gaming addiction may be influenced by higher levels of sensation seeking (e.g. Lin \& Tsai, 2002; Mehroof \& Griffiths, 2010), which is highly correlated and shares some similarities, such as disinhibition, with impulsivity (Steinberg et al., 2008).

On the other hand, Burnay, Billieux, Blairy, and Larøi (2015) and Müller, Dreier, Beutel, and Wölfling (2016) did not confirm that higher sensation seeking predicts (or is a characteristic of) gaming addiction. Billieux et al. (2015), showed in a cluster analysis that only some of the problematic gamers are characterized by higher impulsivity, while in others it was escapism that contributed to the problem. The comparability of these studies, however, is limited as they worked with various sample types (e.g., a convenient sample in Billieux et al., 2015 and Burnay et al., 2015; a clinical sample in Müller et al., 2016; and longitudinal panel data in Gentile et al., 2011), different measurements of both gaming addiction and impulsivity, and different analytical strategies..

Research on impulsivity and online gaming has to reflect upon the inverse proportionality between impulsivity and age: impulsivity decreases towards adulthood (Steinberg et al., 2008) and it changes its structural features with age (Leshem \& Glicksohn, 2007). Gaming addiction seems to be more prevalent among younger people and many studies have been conducted with adolescent samples (Kuss \& Griffiths, 2012). Thus, it is not certain to what extent higher impulsivity in gamers is specifically explained by their young age and whether impulsivity is still a predictor of addiction in older age. For instance, in a study by Choi et al. (2014) that claimed that higher impulsivity is attributed to gaming addiction, internet gamers in treatment were significantly younger (in their late teens and early 20s) compared to gamblers and the healthy control group (who were about seven years older on average).

Research on the personality factors of those at risk of gaming addiction also showed that they are often characterized by lower social competence (Blinka \& Mikuška, 2014), introversion, and low openness (Müller, Beutel, \& Wölfling, 2014), and by a schizoid personality type (Kuss \& Griffiths, 2012). Such traits are characterized by an inhibition in behaviour, while impulsivity is disinhibited behaviour and, as such, is often related to traits like extraversion (Brunas-Wagstaff, Bergquist, Richardson, \& Connor, 1995).

This study seeks to investigate the role of impulsivity in online gaming addiction while controlling for gender, the frequency of online gaming, and especially age. We use the concept of dysfunctional impulsivity (Dickam, 1990) that focuses on the negative sides of impulsive behaviour - a tendency to act with less forethought and an inability to control one's behaviour despite negative consequences. Although impulsivity is sometimes perceived as a negative trait, the Dickman study (1990) supports the existence of impulsivity as either having positive or negative consequences. Thus, impulsivity may be understood as having two dimensions - functional and dysfunctional. We decided to use dysfunctional impulsivity rather than functional impulsivity because it is more strongly associated with the inability to delay gratification and with disorderliness, the tendency to ignore hard 
facts, and the lack of concern (Jones \& Paulhus, 2011; Maccallum et al., 2007). For comparative purposes, we also investigate the role of dysfunctional impulsivity in engaged, but not yet pathological, gamers. Online gaming addiction is often confused with the frequency of play, but the two, although correlated, represent independent phenomena, i.e. long hours of play do not necessarily indicate addiction. The time spent gaming (frequency of play) is also included in the analysis because we would like to examine the pure effect of dysfunctional impulsivity on the pathology without the effect of time spent online.

\section{Methods}

\section{Participants}

The data come from an online survey of Czech and Slovak players of Massive Multiplayer Online Games (MMOG). The study was advertised in online gaming magazines, on gaming discussion forums, and on guild websites, and targeted the core of the Czech and Slovak gaming community. Heavy players were expected to account for the majority of the sample. Incentives in the form of lottery prizes were used to solicit higher participation. The questionnaire was published in Czech on the Lime Survey platform in spring 2014. A total of 1,463 players (aged 12-69; $M=24.40, S D=6.48 ; 90.80 \%$ male) filled out the questionnaire sufficiently in order to be included in the analysis. Participants spent between zero and 92 hours playing online games per week $(M=$ 27.50, $S D=16.05$ ).

\section{Measures}

Online gaming addiction was measured using the Addiction-Engagement Questionnaire (AEQ), which is a 24item tool with response options on a four-point scale (1 - strongly disagree; 4 -strongly agree). The tool distinguishes between online gaming addiction (12 items) and high engagement in online games (12 items). The addiction subscale focuses on core addiction criteria, such as conflict, behavioural salience, and withdrawal, while the engagement subscale measures peripheral addiction criteria, such as cognitive salience, euphoria, and tolerance (Charlton \& Danforth, 2007, 2010). Both subscales had sufficient internal consistency (Cronbach's alpha 0.80 for addiction and Cronbach's alpha 0.72 for high engagement). We created two new combined variables for addiction and engagement as mean scores of the respective subscales ranging from 1 to $4\left(M_{\mathrm{ADD}}=\right.$ $1.73, S D_{\mathrm{ADD}}=0.48 ; M_{\mathrm{ENG}}=2.82, S D_{\mathrm{ENG}}=0.38$.

The frequency of online gaming, expressed in weekly playing hours, was constructed as a combined measure using two open-ended questions: "In the last three months, how much time (in hours) did you usually spend gaming on a normal working day?" and "In the last three months, how much time (in hours) did you usually spend gaming on a day off?" Respondents who did not play in the last three months (i.e., obtained zero in the combined frequency variable) were excluded from the analysis.

Dysfunctional impulsivity was measured using the 12 items of the respective subscale of Dickman's (1990) Impulsivity Inventory. The items were measured as a yes/no dichotomy; the scale had sufficient internal consistency (Cronbach's alpha 0.79). The final dysfunctional impulsivity variable was created as a mean score and ranged from 0 to $1(M=0.25, S D=0.24)$, and was positively skewed $(S=0.959, S E=0.06)$.

\section{Data Analysis}

Pearson's correlation coefficients were calculated for all variables. Two separate regression models were constructed using hierarchical linear regression to determine the association between online gaming addiction/engagement and dysfunctional impulsivity, while controlling for age, gender, and the frequency of online gaming. Given the age characteristics of the sample, we did not control for education because it proved to be age-dependent.

The assumptions of regression analysis were met. Multicollinearity was not a problem because all correlation coefficients were relatively low with values of a maximum of 0.35 ; VIF $=1.046$, tolerance $=0.940$. Autocorrelation also was not observed - the value of Durbin-Watson was 1.934, which indicates uncorrelated residuals. The 
residuals were approximately normally distributed and the assumption of independence was not violated in this study.

Based on the cut-off point of two Standard Deviations (SD) above the sample mean, we identified addicted online gamers and dysfunctionally impulsive gamers; this discrimination strategy had already been used successfully elsewhere (Blinka et al., 2015). To answer the question about differences in the structure of addiction between those who suffer from dysfunctional impulsivity and those who do not, we employed a set of chi-square tests to compare the distribution of the individual addiction criteria.

\section{Results}

Pearson's correlation coefficient showed significant association between the main constructs. Dysfunctional impulsivity and age were negatively correlated, confirming that impulsivity is a natural developmental characteristic of adolescence. There was a moderate positive relationship between dysfunctional impulsivity and addiction, while only a weak positive relationship with gaming engagement (see Table 1). The outcomes of the hierarchical linear regression showed that the effect of impulsivity on addiction was partially mediated by age and hours spent gaming weekly (see Table 2). Although dysfunctional impulsivity was a good predictor of gaming addiction $(\beta=.252$ ), it actually explained only about $7 \%$ of the variance of addiction. The same analysis with gaming engagement as a dependent variable revealed a similar pattern of associations; however, engagement appears to be more gender-dependent and less the result of dysfunctional impulsivity.

When comparing addicted gamers (who scored 2 or more SDs above the sample mean on the AEQ addiction subscale, $n=46$ ) who are impulsive (above 2 SDs on dysfunctional impulsivity, $n_{\text {IMPAADD }}=9$ ) and those who are not (less than 2 SDs, $n=37$ ), problematic gamers high on impulsivity had similar patterns of addiction criteria as non-impulsive gamers, with one exception: they had, despite small sample sizes, a significantly higher tendency to relapse $\left(\chi^{2}(3, n=41)=8.27, p<0.05\right)$. Relapse and reinstatement were measured by the following item: I have made unsuccessful attempts to reduce the time I spend playing.

Table 1. Correlations of the Main Study Variables.

\begin{tabular}{|c|c|c|c|c|c|}
\hline & (1) & $(2)$ & (3) & (4) & (5) \\
\hline Addiction (1) & - & $.30 * \star$ & $.31 * \star$ & $.35 * \star$ & $-.19 * \star$ \\
\hline Engagement (2) & & - & $.11 * *$ & $.24 * *$ & $-.05 *$ \\
\hline Dysfunctional impulsivity (3) & & & - & $.16^{\star *}$ & $-.17 * *$ \\
\hline Frequency of play (4) & & & & - & $-.20 * *$ \\
\hline Age (5) & & & & & - \\
\hline
\end{tabular}

Note: ${ }^{*} p<.01 ; * p<.05$

Table 2. Linear Regression Models for Online Gaming Addiction.

\begin{tabular}{|c|c|c|c|c|c|c|c|c|c|}
\hline & \multicolumn{3}{|c|}{ Model 1} & \multicolumn{3}{|c|}{ Model 2} & \multicolumn{3}{|c|}{ Model 3} \\
\hline & $\boldsymbol{b}$ & $\beta$ & Sig. & $\boldsymbol{b}$ & $\beta$ & Sig. & $\boldsymbol{b}$ & $\beta$ & Sig. \\
\hline Constant & 1.96 & & .00 & 1.63 & & .00 & 1.46 & & .00 \\
\hline Gender $($ Female $=1$, Male=2) & 0.05 & -.03 & .26 & 0.02 & .01 & .57 & 0.03 & .02 & .43 \\
\hline Age & -0.01 & -.19 & .00 & -0.01 & -.12 & .00 & -0.01 & -.09 & .00 \\
\hline Frequency of gaming & & & & 0.01 & .32 & .00 & 0.01 & .29 & .00 \\
\hline Dysfunctional impulsivity & & & & & & & 0.51 & .25 & .00 \\
\hline$F$ & & 27.23 & & & 75.12 & & & 88.11 & \\
\hline$p$ & & $<.00$ & & & $<.00$ & & & $<.00$ & \\
\hline R Square & & .04 & & & .13 & & & .20 & \\
\hline
\end{tabular}


Table 3. Linear Regression Models for High Engagement in Online Gaming.

\begin{tabular}{|c|c|c|c|c|c|c|c|c|c|}
\hline & \multicolumn{3}{|c|}{ Model 1} & \multicolumn{3}{|c|}{ Model 2} & \multicolumn{3}{|c|}{ Model 3} \\
\hline & $\boldsymbol{b}$ & $\beta$ & Sig. & $\boldsymbol{b}$ & $\beta$ & Sig. & $\boldsymbol{b}$ & $\beta$ & Sig. \\
\hline Constant & 3.18 & & .00 & 2.98 & & .00 & 2.94 & & .00 \\
\hline Gender $($ Female $=1$, Male $=2)$ & -0.15 & -.11 & .00 & -0.17 & -.12 & .00 & -0.16 & -.12 & .00 \\
\hline Age & 0.00 & .00 & .05 & 0.00 & .00 & .10 & 0.00 & .01 & .70 \\
\hline Frequency of gaming & & & & 0.01 & .25 & .00 & 0.01 & .24 & .00 \\
\hline Dysfunctional impulsivity & & & & & & & 0.12 & .08 & .00 \\
\hline$F$ & & 11.42 & & & 38.91 & & & 31.45 & \\
\hline$P$ & & $<.00$ & & & $<.00$ & & & $<.00$ & \\
\hline R Square & & .01 & & & .07 & & & .08 & \\
\hline
\end{tabular}

\section{Discussion}

The aim of this study was to evaluate the role of dysfunctional impulsivity in excessive online gaming, both in a pathological and non-pathological way. The results are mixed. On one hand, impulsivity was significant and a rather strong predictor of online gaming addiction. The strength of the association was similar to the association between the frequency of gaming and addiction. However, adding dysfunctional impulsivity to the model increased the variance of addiction by only $7 \%$. This likely means that higher levels of dysfunctional impulsivity elevate the risk of developing the symptoms of addiction, but impulsivity itself is not the most important factor behind gaming addiction.

According to Müller et al. (2016) sensation seeking (and, thus, impulsivity to some extent) is lower in addicted gamers, while Billieux et al. (2015) showed that for certain groups of pathological gamers some impulsive traits are typical, e.g. the lack of premeditation and the lack of perseverance. Our findings seem be in line with these views - impulsivity is probably involved with gaming addiction, but its contribution is rather small; gaming addiction has to be accompanied by other individual traits or risk factors; and/or gaming addiction is typical only for specific groups of gamers. Other factors may be more important, such as introversion, low conscientiousness (Müller et al., 2014), low social competence (Blinka \& Mikuska, 2014), and low self-esteem (Ko, Yen, Chen, Chen, \& Yen, 2005). Müller et al. (2014) found that addicted gamers differed from gamblers and other addicts in their low extraversion. But it is extraversion that is related to higher impulsiveness (Brunas-Wagstaff et al., 1995) and, thus, high impulsivity is not likely to be significant in gaming addiction. Our study is in line with this assumption.

The fact that the effect of dysfunctional impulsivity on high gaming engagement (i.e. on heavy gaming involvement, which is not defined just by time spent online but also by peripheral indicators of addiction and which is not pathological) was negligible, may point to two issues. First, this study brings another piece of evidence that gaming addiction and engagement are two distinct concepts, as previously shown by Charlton and Danforth (2007, 2010): gaming frequency is similar in both conditions while the psychological factor (i.e., dysfunctional impulsivity) played a role only in addiction. Second, since dysfunctional impulsivity differentiated addiction from engagement in this study, the role of impulsivity in gaming addiction should not be overlooked despite the overall small effect. Highly impulsive addicted gamers were also more likely to report a relapse into problematic behaviour than those who were non-impulsive. This is in line with the results of the longitudinal study by Gentile et al. (2011), who found higher impulsivity in gamers who report problems over a longer period of time. This may be an important issue with practical applications because such a group of gamers may need a special approach in treatment that is more focused on the prevention of relapse and the reinstatement of the problematic behaviour. In previous research, Maccallum et al. (2007) also found that dysfunctional impulsivity in gamblers is related to poorer response to treatment. This is in line with the conceptualization of dysfunctional impulsivity - in other words, quick and careless maladaptive decision-making with a propensity to immediate gratification. Further research is needed to evaluate whether impulsive gamers also face further negative consequences compared to non-impulsive gamers (e.g. it may be possible that they spend more money on extra in-game content). 
Interestingly, age, although a significant predictor of addiction in the first model, lost its effect after the frequency of gaming and impulsivity entered the analysis. This confirms our assumption that age and impulsivity interact. Many studies focused on adolescents or did not control for age when analysing impulsivity and gaming addiction; indeed, the results that younger gamers are more likely to be addicted could be expected. Moreover, some studies compared the levels of impulsivity in various addictions, but the group of online gamers was younger than the other addicts and the control group (e.g. Choi et al., 2014), which might bias the results. The structure of our sample helped to overcome this problem because it includes a large number of both adolescents and adults. Based on our results, it seems that younger gamers are more likely to also fulfil the addiction criteria because they are in a developmental stage that is characterised by higher levels of impulsivity - impulsivity and sensation seeking peak during adolescence and steadily decrease afterward (Leshem \& Glicksohn, 2007; Steinberg et al., 2008).

Several methodological limitations should be mentioned. The study is cross-sectional and it does not allow for the exploration of causality - when we speak of predictors, we do not address the direction of the relationship nor the causality. Convenience sampling and self-selection may lead to biased results due to the potential constraints of the variance. Also, variables used in this study were part of a larger research project, where the dysfunctional impulsivity scale was placed at the end of a questionnaire that took about 30 minutes to complete. This could influence the prevalence of impulsivity as many of the highly impulsive subjects might have quit the questionnaire earlier and this might also explain why impulsivity was heavily skewed in this study. However, Caci, Nadalet, Baylé, Robert, and Boyer (2003) reported a similarly skewed distribution of dysfunctional impulsivity and suggest that this concept is by nature pathological and, thus, rare and far from normal distribution. Also, the discrimination method based on two SDs may fail to distinguish the most problematic gamers in this specific sample, which was not representative for the gaming population, and, due to the recruitment strategy, comprised mainly of heavy gamers. It may, therefore, be assumed that our discrimination method captured only a small sub-sample of the heaviest gamers who fulfilled the criteria of online gaming addiction. Nevertheless, the AEQ was not validated for discriminatory purposes and, as such, it does not provide any other means to identify the problematic players. However, despite the limitations, the main result that dysfunctional impulsivity is a predictor of online gaming addiction, although not a very strong one, should not be overlooked.

\section{Acknowledgement}

The article was supported by grant from Czech Science Foundation (GA15-19221S).

\section{References}

American Psychiatric Association. (2013). Diagnostic and statistical manual of mental disorders (5th ed.). Washington, DC: Author.

Billieux, J., Thorens, G., Khazaal, Y., Zullino, D., Achab, S., \& Van der Linden, M. (2015). Problematic involvement in online games: A cluster analytic approach. Computers in Human Behavior, 43, 242-250.

http://dx.doi.org/10.1016/j.chb.2014.10.055

Blinka, L., \& Mikuška, J. (2014). The role of social motivation and sociability of gamers in online game addiction. Cyberpsychology: Journal of Psychosocial Research on Cyberspace, 8(2). http://dx.doi.org/10.5817/CP2014-2-6

Blinka, L., Skarupova, K., Sevcikova, A., Wölfling, K., Müller, K. W., \& Dreier, M. (2015). Excessive internet use in European adolescents: What determines differences in severity?. International Journal of Public Health, 60, 249256. http://dx.doi.org/10.1007/s00038-014-0635-x

Brunas-Wagstaff, J., Bergquist, A., Richardson, P., \& Connor, A. (1995). The relationships between functional and dysfunctional impulsivity and the Eysenck personality questionnaire. Personality and Individual Differences, 18, 681-683. http://dx.doi.org/10.1016/0191-8869(94)00202-4 
Burnay, J., Billieux, J., Blairy, S., \& Larøi, F. (2015). Which psychological factors influence Internet addiction? Evidence through an integrative model. Computers in Human Behavior, 43, 28-34.

http://dx.doi.org/10.1016/j.chb.2014.10.039

Caci, H., Nadalet, L., Baylé, F. J., Robert, P., \& Boyer, P. (2003). Functional and dysfunctional impulsivity: Contribution to the construct validity. Acta Psychiatrica Scandinavica, 107(1), 34-40.

http://dx.doi.org/10.1034/j.1600-0447.2003.01464.x

Charlton, J. P., \& Danforth, I. D. (2007). Distinguishing addiction and high engagement in the context of online game playing. Computers in Human Behavior, 23, 1531-1548. http://dx.doi.org/10.1016/j.chb.2005.07.002

Charlton, J. P., \& Danforth, I. D. (2010). Validating the distinction between computer addiction and engagement: online game playing and personality. Behaviour \& Information Technology, 29, 601-613.

http://dx.doi.org/10.1080/01449290903401978

Choi, S. W., Kim, H., Kim, G. Y., Jeon, Y., Park, S., Lee, J. Y., ... \& Kim, D. J. (2014). Similarities and differences among Internet gaming disorder, gambling disorder and alcohol use disorder: A focus on impulsivity and compulsivity. Journal of Behavioral Addictions, 3, 246-253. http://dx.doi.org/10.1556/JBA.3.2014.4.6

Dickman, S. J. (1990). Functional and dysfunctional impulsivity: Personality and cognitive correlates. Journal of Personality and Social Psychology, 58, 95-102. http://dx.doi.org/10.1037/0022-3514.58.1.95

el-Guebaly, N., Mudry, T., Zohar, J., Tavares, H., \& Potenza, M. N. (2012). Compulsive features in behavioural addictions: The case of pathological gambling. Addiction, 107, 1726-1734. http://dx.doi.org/10.1111/j.13600443.2011.03546.x

Gentile, D. A., Choo, H., Liau, A., Sim, T., Li, D., Fung, D., \& Khoo, A. (2011). Pathological video game use among youths: A two-year longitudinal study. Pediatrics, 127, e319-329. http://dx.doi.org/10.1542/peds.2010-1353

Grant, J. E., Potenza, M. N., Weinstein, A., \& Gorelick, D. A. (2010). Introduction to behavioral addictions. The American Journal of Drug and Alcohol Abuse, 36, 233-241. http://dx.doi.org/10.3109/00952990.2010.491884

Jentsch, J. D., Ashenhurst, J. R., Cervantes, M. C., Groman, S. M., James, A. S., \& Pennington, Z. T. (2014). Dissecting impulsivity and its relationships to drug addictions. Annals of the New York Academy of Sciences, 1327(1), 1-26. http://dx.doi.org/10.1111/nyas.12388

Jones, D. N., \& Paulhus, D. L. (2011). The role of impulsivity in the Dark Triad of personality. Personality and Individual Differences, 51, 679-682. http://dx.doi.org/10.1016/j.paid.2011.04.011

Ko, C. H., Yen, J. Y., Chen, C. C., Chen, S. H., \& Yen, C. F. (2005). Gender differences and related factors affecting online gaming addiction among Taiwanese adolescents. The Journal of Nervous and Mental Disease, 193, $273-277$. http://dx.doi.org/10.1097/01.nmd.0000158373.85150.57

Kuss, D. J., \& Griffiths, M. D. (2012). Internet gaming addiction: A systematic review of empirical research. International Journal of Mental Health and Addiction, 10, 278-296. http://dx.doi.org/10.1007/s11469-011-9318-5

Leshem, R., \& Glicksohn, J. (2007). The construct of impulsivity revisited. Personality and Individual Differences, 43, 681-691. http://dx.doi.org/10.1016/j.paid.2007.01.015

Liau, A. K., Neo, E. C., Gentile, D. A., Choo, H., Sim, T., Li, D., \& Khoo, A. (2015). Impulsivity, self-regulation, and pathological video gaming among youth testing a mediation model. Asia-Pacific Journal of Public Health, 27, NP2188-NP2196. http://dx.doi.org/10.1177/1010539511429369

Lin, S. S., \& Tsai, C. C. (2002). Sensation seeking and internet dependence of Taiwanese high school adolescents. Computers in Human Behavior, 18, 411-426. http://dx.doi.org/10.1016/S0747-5632(01)00056-5 
Lubman, D. I., Yücel, M., \& Pantelis, C. (2004). Addiction, a condition of compulsive behaviour? Neuroimaging and neuropsychological evidence of inhibitory dysregulation. Addiction, 99, 1491-1502.

http://dx.doi.org/10.1111/j.1360-0443.2004.00808.x

Maccallum, F., Blaszczynski, A., Ladouceur, R., \& Nower, L. (2007). Functional and dysfunctional impulsivity in pathological gambling. Personality and Individual Differences, 43, 1829-1838.

http://dx.doi.org/10.1016/j.paid.2007.06.002

Mehroof, M., \& Griffiths, M. D. (2010). Online gaming addiction: The role of sensation seeking, self-control, neuroticism, aggression, state anxiety, and trait anxiety. Cyberpsychology, Behavior, and Social Networking, 13, 313316. http://dx.doi.org/10.1089/cpb.2009.0229

Müller, K. W., Beutel, M. E., \& Wölfling, K. (2014). A contribution to the clinical characterization of Internet addiction in a sample of treatment seekers: Validity of assessment, severity of psychopathology and type of comorbidity. Comprehensive Psychiatry, 55, 770-777. http://dx.doi.org/10.1016/j.comppsych.2014.01.010

Müller, K. W., Dreier, M., Beutel, M. E., \& Wölfling, K. (2016). Is Sensation Seeking a correlate of excessive behaviors and behavioral addictions? A detailed examination of patients with gambling disorder and internet addiction. Psychiatry Research, 242, 319-325. http://dx.doi.org/10.1016/j.psychres.2016.06.004

Potenza, M. N. (2006). Should addictive disorders include non-substance-related conditions?. Addiction, 101(s1), 142-151. http://dx.doi.org/10.1111/j.1360-0443.2006.01591.x

Steinberg, L., Albert, D., Cauffman, E., Banich, M., Graham, S., \& Woolard, J. (2008). Age differences in sensation seeking and impulsivity as indexed by behavior and self-report: Evidence for a dual systems model. Developmental Psychology, 44, 1764-1778. http://dx.doi.org/10.1037/a0012955

Verdejo-García, A., Lawrence, A. J., \& Clark, L. (2008). Impulsivity as a vulnerability marker for substance-use disorders: Review of findings from high-risk research, problem gamblers and genetic association studies. Neuroscience \& Biobehavioral Reviews, 32, 777-810. http://dx.doi.org/10.1016/j.neubiorev.2007.11.003

Volkow, N. D., Fowler, J. S., \& Wang, G. J. (2003). The addicted human brain: Insights from imaging studies. The Journal of Clinical Investigation, 111, 1444-1451. http://dx.doi.org/10.1172/JCl18533

Walther, B., Morgenstern, M., \& Hanewinkel, R. (2012). Co-occurrence of addictive behaviours: Personality factors related to substance use, gambling and computer gaming. European Addiction Research, 18, 167-174.

http://dx.doi.org/10.1159/000335662

\section{Correspondence to:}

Lukas Blinka

Faculty of Social Studies, MU

Jostova 10

602 00, Brno

Czech Republic

Tel: +420 549493393

Email: lukasblinka(at)gmail.com 


\begin{abstract}
About authors
Lukas Blinka is a Senior Research Fellow and Assistant Professor at the Faculty of Social Studies, Masaryk University. His research interests comprise effects of use and overuse of digital media on well-being - in particular, excessive online gaming or excessive use of the internet for sexual purposes.

Kateřina Škařupová is a senior researcher at the Institute on Research of Children, Youth and Family and an assistant professor in the Department of Media Studies and Journalism, both at Masaryk University. Her research interests cover a broad area of drug use and substance and behavioral addiction.

Kristina Mitterova is a graduate student of psychology at Masaryk University. Her study and research interests include facial emotion recognition, impulsivity and cognitive neuropsychology. Kristina interned at CEITEC (Central European Institute of Technology in Brno, Czech Republic) in neurobehavioral research and is currently on an exchange program in Canada, where she has an internship at the Face Perception Lab.
\end{abstract}

